\title{
Building on planet Mars student project
}

\author{
A. Nussbaumer \& P. Zurbruegg \\ ENAC, EPFL, Lausanne, Switzerland \\ S. Erkman \& T. Besson \\ FGSE, UNIL, Lausanne, Switzerland
}

\begin{abstract}
In the case of such a very special building project, the crucial stake for sustainable development is the fact that space systems are extreme cases of environmental constraints. Indeed, they constitute an interesting model as an analogy can be made between Martian utmost conditions and some of the possible extreme one's that Earth might soon face. The didactic objective of the project is to use the context of a building on Mars to teach an approach which raises the students awareness to design and plan all steps of a building in a sustainable way, i.e. build, with the available resources, living spaces that satisfy human needs and leave as intact as possible the external environment. The paper presents the approach and the feedback of this student project, more specifically ENAC Learning Unit", which involved 17 students from environmental, civil engineering and architecture sections from EPFL. All the same, it involved professors from all three domains, as well as aerospace and Mars specialists, which gave seminars during the course of the semester. The students were separated in groups, and the project consisted of two phases: 1) analysis of the context and resources, 2) project design and critic. Both organisational, technical and pedagogical aspects of the experience are presented. The outcome was very positive, with students experiencing for their first time multidisciplinary work and the iterative process of design under multiple constraints.
\end{abstract}

\section{INTRODUCTION}

\subsection{Academic context ENAC}

The ENAC school (faculté d'Environnement Naturel, Architectural et Construit) at EPFL is composed of the sections of architecture, civil engineering and environmental sciences and engineering. One of ENAC's strategy is « Design \& Build Together », which responds to the growing need for increased cooperation on projects between engineers and architects. It is implemented by various actions in teaching provided by the three different educational programs as explained below.

ENAC teaching activities evolve around land planning themes for all three programs. The teaching platform aims at developing learning synergies between students so as to train, from the early stages of higher education, both engineers and architects able to work together on spatial development issues. At bachelor level, these activities are obligatory.

Apart from common courses, the first practical teaching offer is called "ENAC Weeks". These are one-week full time courses, which all $2^{\text {nd }}$ year bachelor students choose from a selection. It enables them to work together on a joint theme but using their specific skills. "ENAC weeks" are offered by various groups of ENAC lecturers and each brings together typically some twenty students from the three different programs (the number from each program being at the prorata of the total).

The second practical teaching offer occurs one year later, for the $6^{\text {th }}$ semester, is called "ENAC Learning Units". Like the ENAC Weeks, this course enables students from Architecture, Civil and Environmental Engineering to review a specific theme in depth with 4 hours of courses and exercises per week during the spring term. They allow the students to establish tan- 
gible links between theory and practice. They concern real complex problems, connected to the natural and built environment.

To approach these problems, the students are brought to work in multidisciplinary teams and to acquire actively knowledge through the exercise of the formulation of a problem and the search for solutions. The themes of the "ENAC Learning Units" bring students and teachers together as partners of a multidisciplinary search. Additionally at the master level, students can choose to work on semester projects putting in practice the « Design \& Build Together ».

\subsection{Objectives of building on planet Mars course "ENAC Learning Unit"}

The theme "Building on planet Mars" was chosen because it constitutes a case of extreme environmental constraints and as such, it raises the same questions than sustainable design. Moreover, Mars conquest is also an actual theme with the landing of Curiosity in August 2012 and makes you dream, especially as a future engineer or architect.

The pedagogical and didactic objectives were to use this very special context to force a return to the basic principles of the building act: use available resources (whenever possible local and question importation) in the most efficient ways, design envelopes able to protect inside environment from external conditions, create living spaces that satisfy human needs, etc. The approach was assuming the current and continuous increase of similar terrestrial constraints, such as resources scarcity and waste emission dissipation $\left(\mathrm{CO}_{2}\right.$, nitrogen, phosphorus, fertilizers, micropollutants, etc.) coming from the activities of the "industrial" ecosystem. With this industrial ecology perspective [Erkman 1997], one's must well integrate the perception of both Earth and Mars limits (no way to cheat with sinks and stocks), by developing highly efficient recycling systems. Thus, there is an analogy between Martian utmost conditions and some of the possible extreme one's that Earth might soon face. Then, building on planet Mars constitutes a relevant model for the students to think globally about sustainability and « Design \& Build Together ». This pushed the students to tackle challenging interface problems and thus go beyond multidisciplinary towards interdisciplinary work. Indeed, they constitute an interesting model for the students to think globally about sustainability in conditions harsher than on planet Earth or Spaceship Earth as Buckminster Fuller used to call it [1].

The project aim at proposing different designs for a Martian base hosting 30 "colons" for long-term missions, assuming previous exploratory manned missions to Mars had been made. The students had to consider the available local resources and state which others should be imported from Earth. Designing very small but well organized living spaces, managing food as well as energy resources and creating closed loops for the artificial ecological system were of paramount importance.

\section{COURSE ORGANISATION AND DEVELOPMENT}

The Learning Unit lasted one semester of 12 weeks. It was separated into two phases: 1) analysis of context, planet and human needs, 2) design of base. The students, 17 in total, attended several seminars given by the professors on industrial ecology, closed loop ecological systems, building systems, energy, climate on Mars. Furthermore, four seminars from experts in space exploration were also given: Pierre Brisson (president of Mars society, Switerland) [Brisson 2012], Dr. Anton Ivanov (Space Center, EPFL) [Ivanov 2012], Dr. Christophe Lasseur (R\&D coordinator, MELiSSA project, ESA) [Lasseur 2012] and Prof. Claude Nicollier (former Swiss astronaut, EPFL) [Nicollier 2012].

In the first phase, the students were separated into five groups, each group dealing with a particular theme of the context: vital needs, climatic conditions, material resources, energetic resources, and living on Mars scenarios. Every week, each group reported to and discussed with the professors. At the end of the first phase, the groups presented orally their results and submitted each a written report, available then to everyone.

For the second phase, a recombination into three larger groups, with specialists from the different themes and the different programs, was made. Each group was assigned one type of base: on the ground, into a natural shelter, and underground. Using the outcome from phase one, the groups then proposed their vision for a self-sufficient martian base for 30 colons. As before, 
control of student work progress was continuous through weekly discussions with the groups. And at the semester end, the groups presented orally their Martian base proposition and submitted each a written report. Grading of the students was done by combining partial grades given for each phase.

\section{OUTCOMES}

\subsection{Phase 1, analysis of context}

The five following themes were given by the professors: vital needs, climatic conditions, material resources, energetic resources and living on Mars. The five groups were formed on a voluntary basis but also influenced by their program (architecture, civil or environmental engineering). Each theme was studied and resulted in recommendations regarding, for example:

- the location of the base: not at the poles due to limited solar energy resource and owing to the high probability of ice water under the surface at different latitudes;

- artificial air composition, volume: $78 \% \mathrm{~N}_{2}, 21.97 \% \mathrm{O}_{2}$ and $0.03 \% \mathrm{CO}_{2}$, a human needing $1.2 \mathrm{~kg} \mathrm{O}_{2}$ per day, minimum pressure 0.8 bars, and with humidity between 25 and $70 \%$;

- eating, drinking: 13'000 kJ per day and person, provided essentially by breeding crops which requires a minimum of $40 \mathrm{~m}^{2}$ per person, $30 \mathrm{lt}$ of water per day and person (including washing but not breeding water);

- $\quad$ energy resources: one mini-nuclear power plant needed (lasting for the first 15 years), solar cells, need for a reliable energy storage (fuel cells) because of dust tempests that can last for months;

- $\quad$ mean climatic conditions on Mars: gravitation $3.8 \mathrm{~m} / \mathrm{s}^{2}$, temperature $-63^{\circ} \mathrm{C}$, daily temperature amplitude $\pm 50^{\circ} \mathrm{C}$, atmospheric pressure $610 \mathrm{~Pa}$, cycle day/night similar to earth, no seismic or volcanic activities, dust with a fraction of particles smaller $30 \mu \mathrm{m}$ in diameter which are very detrimental to equipment and humans, energy and light radiation from sun approx. $50 \%$ of earth values, presence of cosmic radiation;

- $\quad$ in-situ material resources: alkaline soil with $\mathrm{pH}$ 8.3, containing numerous vital elements such as magnesium, potassium, sodium, chloride, iron. But no ammonium and $0.6 \%$ of perchlorate, which eliminates breeding for food using exclusively Martian soil. Water is available as ice and except for this latest resource, students doubted what can really be exploited at early colonization stage as it requires lots of equipment and energy (using existing Earth information on transformation processes and ecological balances);

- living on Mars: due to travelling windows (one about every 26 Earth months), colons need to stay over 2 years, thus the students made typologies with surfaces including individual sleeping rooms, separating living and working spaces, with multiple redundancy in all functions and using different compartments.

During this phase, the students learned all the basics necessary to predesign of a life system on Mars. They also realized the diversity and huge quantity of knowledge needed for the task.

More specifically, they learned about supply chains, the difficulties in breeding without earth (organic soil and all of its biological, life content), managing energetic resources/storage and, to their own surprise, that it was almost impossible to do without a nuclear power source, that material production processes are extremely energy demanding when you start from scratch. Finally, they learned the need for closing loops as nothing can be left untreated, left to the hazard of nature. Waste is a resource and a danger as well; a complete understanding, controllable and if possible adaptative loops, with control of all ins and outs, is needed. And, as true as no eternal movement exists, not only energy but some type of system cleaning is needed after several loops and losses are inevitable.

\subsection{Phase 2, design of base}

For this second phase, the students were recombined into three larger groups. This recombination was made by the professors in order to have specialists from the different themes from phase 1 and to combine students from the different programs. Each group was assigned one type of base: on the ground (A), into a natural shelter (B), and underground (C). The groups studied their type of base to propose their vision for a self-sufficient Martian base for 30 colons. 
The essential advantages of the natural shelter and the underground base are that the cavern wall can be used to hold the difference between the internal pressure and Mars atmosphere and offer a natural protection against cosmic rays. However, the equipment and uncertainties in building such an infrastructure are larger then staying on the surface.

Looking at group A work, "base on the ground", the student chose to put their base into a cylindrical dome. This creates an artificial atmosphere that could satisfy both the living conditions for humans and for growing crops, but with conditions inside the building (atmosphere 1) and within the dome (atmosphere 2) differing significantly (radiations, temperature, $\mathrm{CO}_{2}$ level, etc.), see figure 1 . The supporting structure is a pressurized "cigar" with longitudinal cables constituting both the main supports for the flooring system of the building the reinforcement of the membrane (a radial cable network is also present within the membrane). In the longitudinal direction, the cylinder is separated into three totally independent modules, lodging 10 colons and producing food for them but designed for 15 persons. If a problem, a contamination occurs or maintenance is needed in one module, only two modules are sufficient for all the colons for a long period. To produce an artificial ecosystem, only way to produce food, the students focused on four main functions:

- $\quad$ food production;

- revitalisation of atmosphere;

- $\quad$ water management: with grey water from kitchen, shower, etc. but not from toilets;

- $\quad$ waste management: dry toilets system, use of green waste to create biogas and humus.

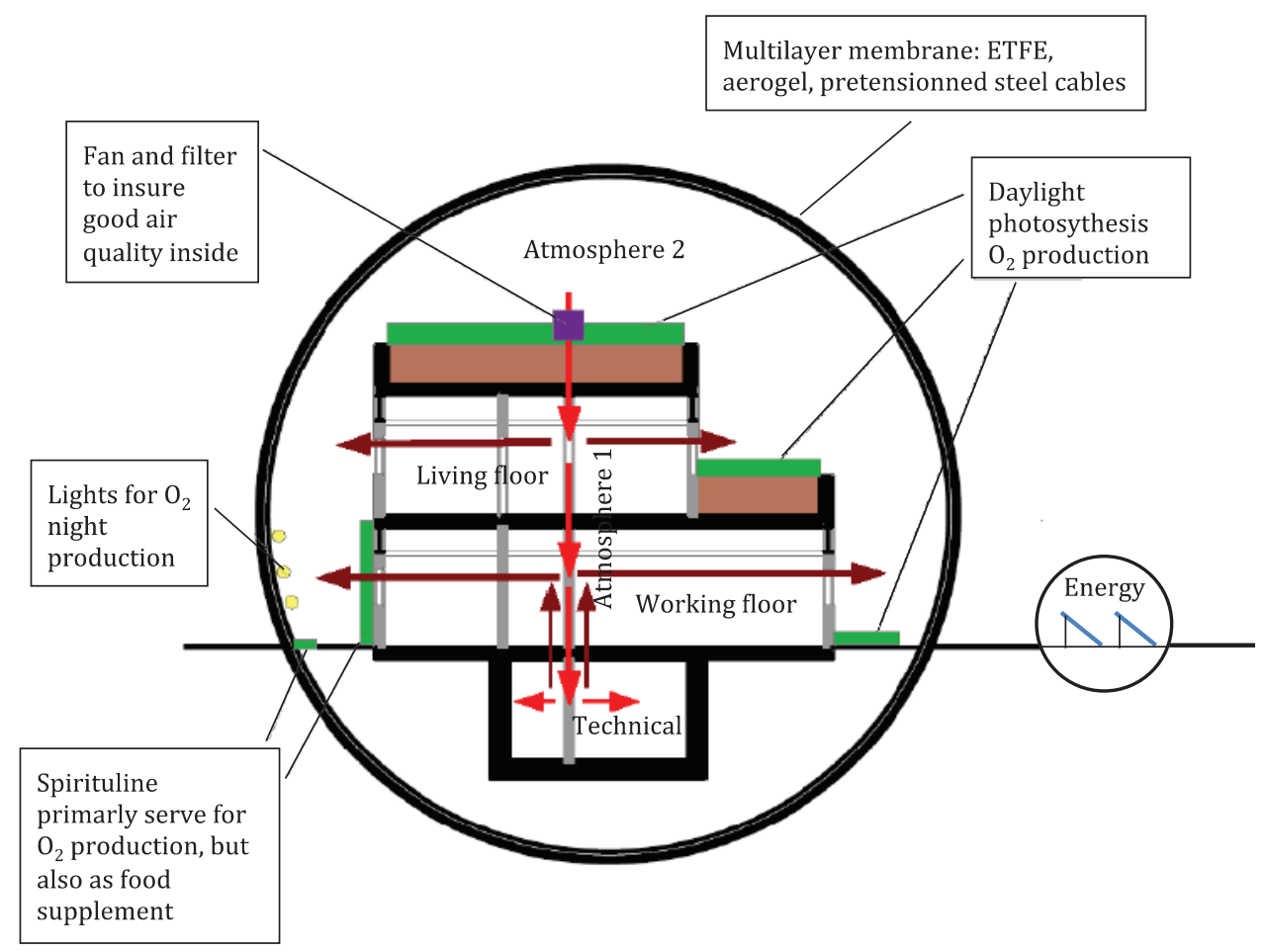

Figure 1. Cross-section of base cylindrical dome (student group A "On the surface"), with scheme of air production, circulation.

In figure 2, the result of the base design of one base with all spaces necessary for living, knowing that the crew will be at least 26 months inside. To emphasize the importance of having natural light, the students from the underground base chose a location near a cliff to build theirs in order to integrate windows. This location is also favourable for drilling from different locations to create the cavern. For food production, greenhouses with natural light, located above the underground living and working spaces, are proposed.

Plants for food production were chosen based on the results of the research project MELiSSA [ESA 2006][Poughon et al 2009]. For the substrat for growing plants, both acquaponic and hydroponic systems have been looked at. 

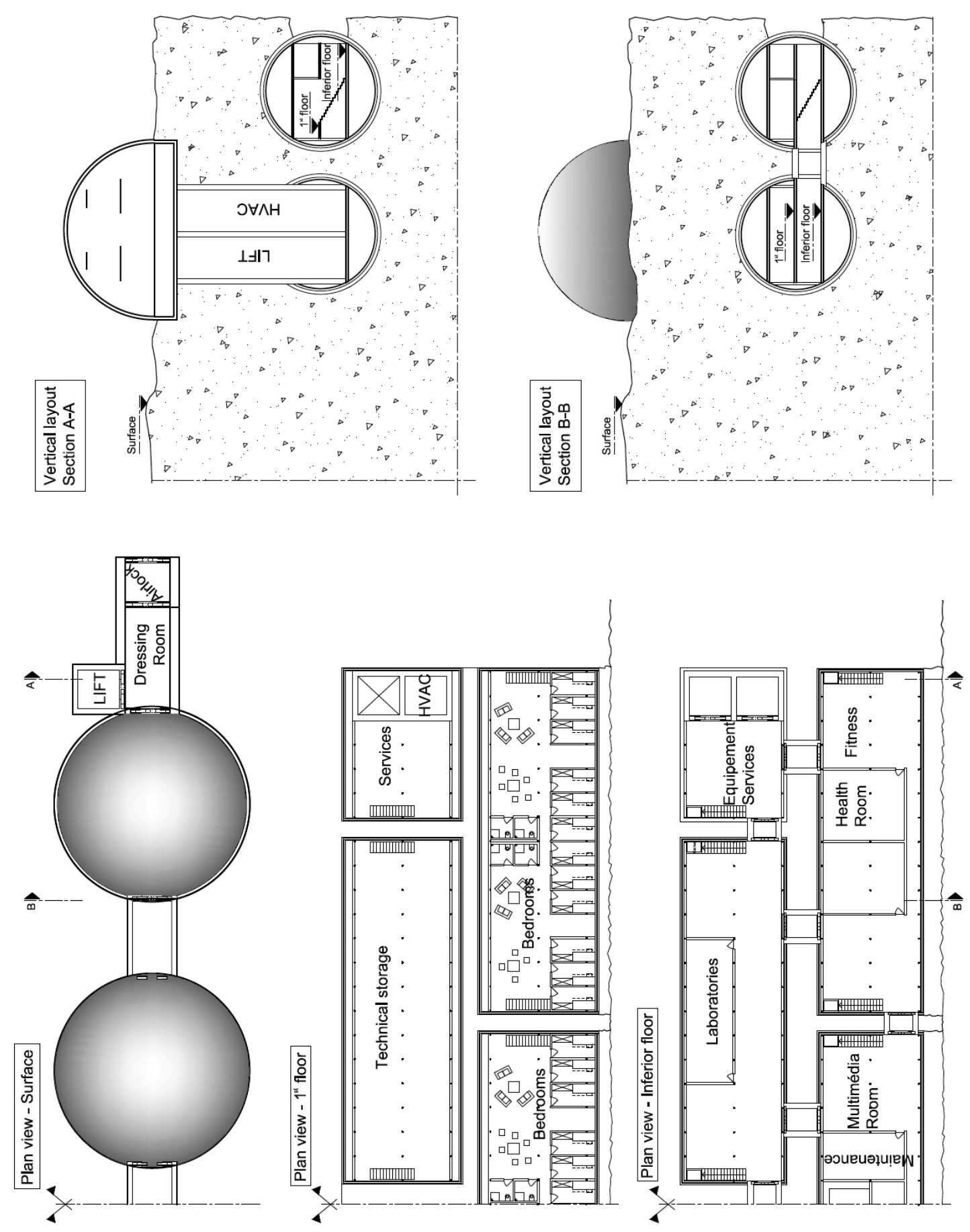

Figure 2. Plan and vertical views of half of the underground base (student group B "Underground"), with spaces definitions.

Figure 3 shows an example of closed loops of exchanges (water, gaz, food). In addition to plants, one can notice that the students imagined that fishes could also be grown. This both helps recycling some pollutants and will give the astronauts more food diversity (because of the length of the stay and impossibility of getting deliveries from Earth).

Out of the reports, the following interesting examples of messages are given:

- $\quad$ no unique way to colonize Mars: necessity to do compromises between many parameters which are function of the available technologies at the time of colonization and of the colonization phase (installed production processes). In the first colonization steps, which might be quite long, most of the materials, devices, infrastructure elements, as well as machines 
will have to be imported from Earth, as no local production can be made (needs anyway imported equipment and robots, astronauts being too precious to become for example miners on Mars). Among those, the production of insulation materials and glass seemed the first and most important to achieve quickly;

- a major challenge lies into the creating of a quasi-closed loop where nothing is wasted and everything get valorized. As of today, one must overdesign any system to compensate for significant losses and count on some deliveries from Earth;

- natural light is a very important point, both for physiological (circadian rythmes regulation) and psychological issues. All groups emphasized it. Even the underground base should have some type of natural light, windows, etc. especially for long-term stays. In this respect, the conference by astronaut Claude Nicollier confirmed the thoughts of the students when he stressed out the importance, and beauty, of being able to see outside the space shuttle through windows.

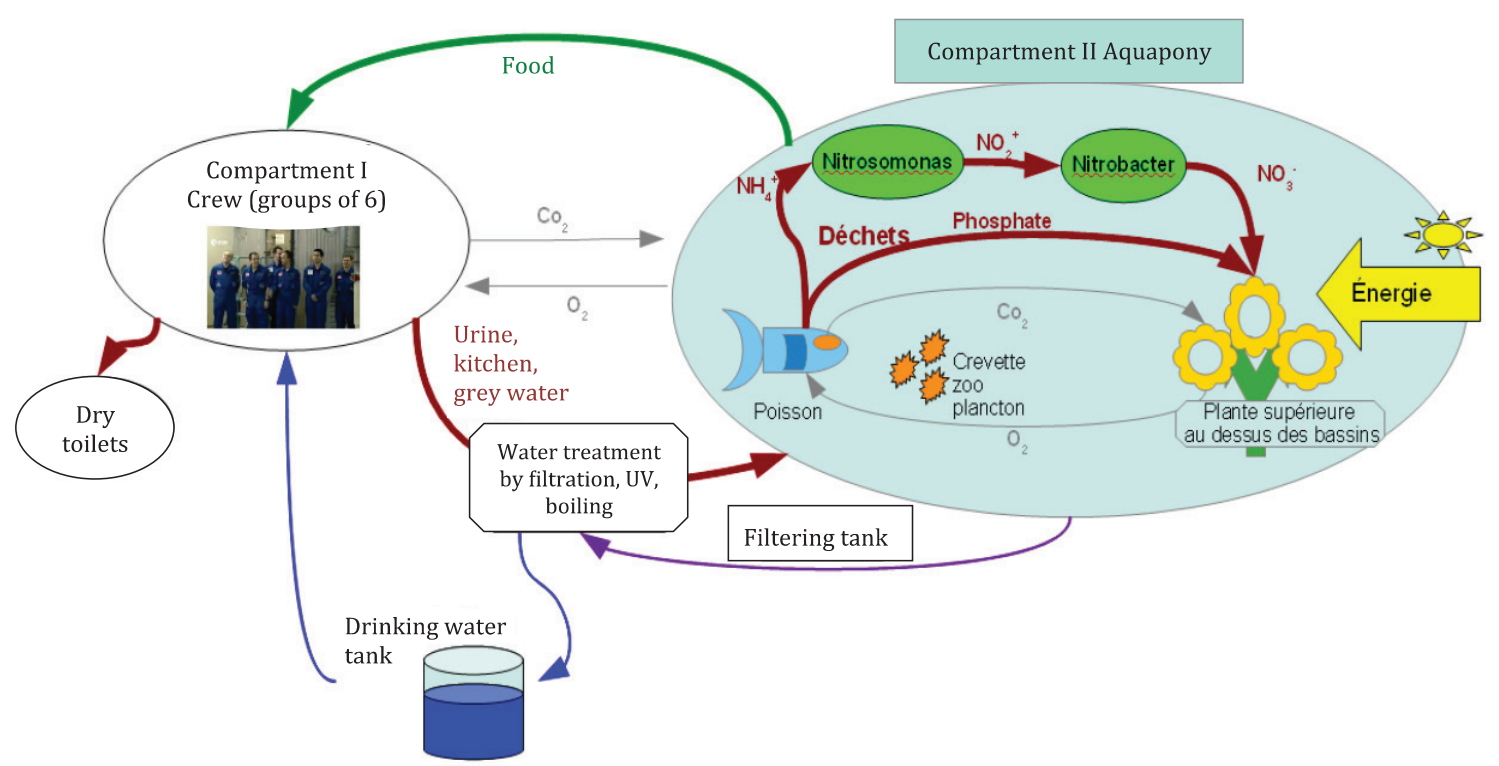

Figure 3. Closed loops of exchanges (water, gaz, food) from student group C, "Underground".

\section{PEDAGOGICAL EVALUATION OF COURSE}

The pedagogical evaluation of the course was done both by the debating at the end of the course with the students and by having the specialised unit at EPFL, namely CRAFT, submitting a questionnaire with 19 questions to all students. Table 1 shows the outcome of the questionnaire (answered by 14 out of 17 students).

This evaluation revealed that the students were globally very pleased with this "ENAC learning unit" course. It also pointed out the following strengths of the course:

- interdisciplinarity in treatment of every thematic. The problematics of energy, of base organization, of infrastructure, of food, etc. were never separated and systematically integrated in the global context and in their interactions;

- $\quad$ relevance and enrichment of composite groups from the three programs;

- $\quad$ relevance of Mars as a pretext for group work. Already after the first phase, we noticed that even not knowing much about the subject to start with, they were very motivated by this new and original subject, and also by the collaboration between the three programs. Thus, they learned a lot and fast;

- the fact that everyone had a key role, which valorise his (her) skills and academic background (program);

- mutual presentations of the works at the end of both project phases, with questions and discussions about ideas or directions taken by the other groups;

- contributions from the external presenters directly or indirectly involved in Space programs (seminars from Pierre Brisson, Prof. Claude Nicollier and Christophe Lasseur). These pre- 
senters succeeded at transferring their passion for space exploration, by transmitting to students the adequate level of information, regarding the time available and the broad audience profiles;

- $\quad$ the follow-up and grading system combining oral presentations and written reports. This allowed to give individual grades to students since the groups where not the same all along;

- $\quad$ the participating and dynamic atmosphere during the course.

Table 1. Outcome of pedagogical evaluation of the course.

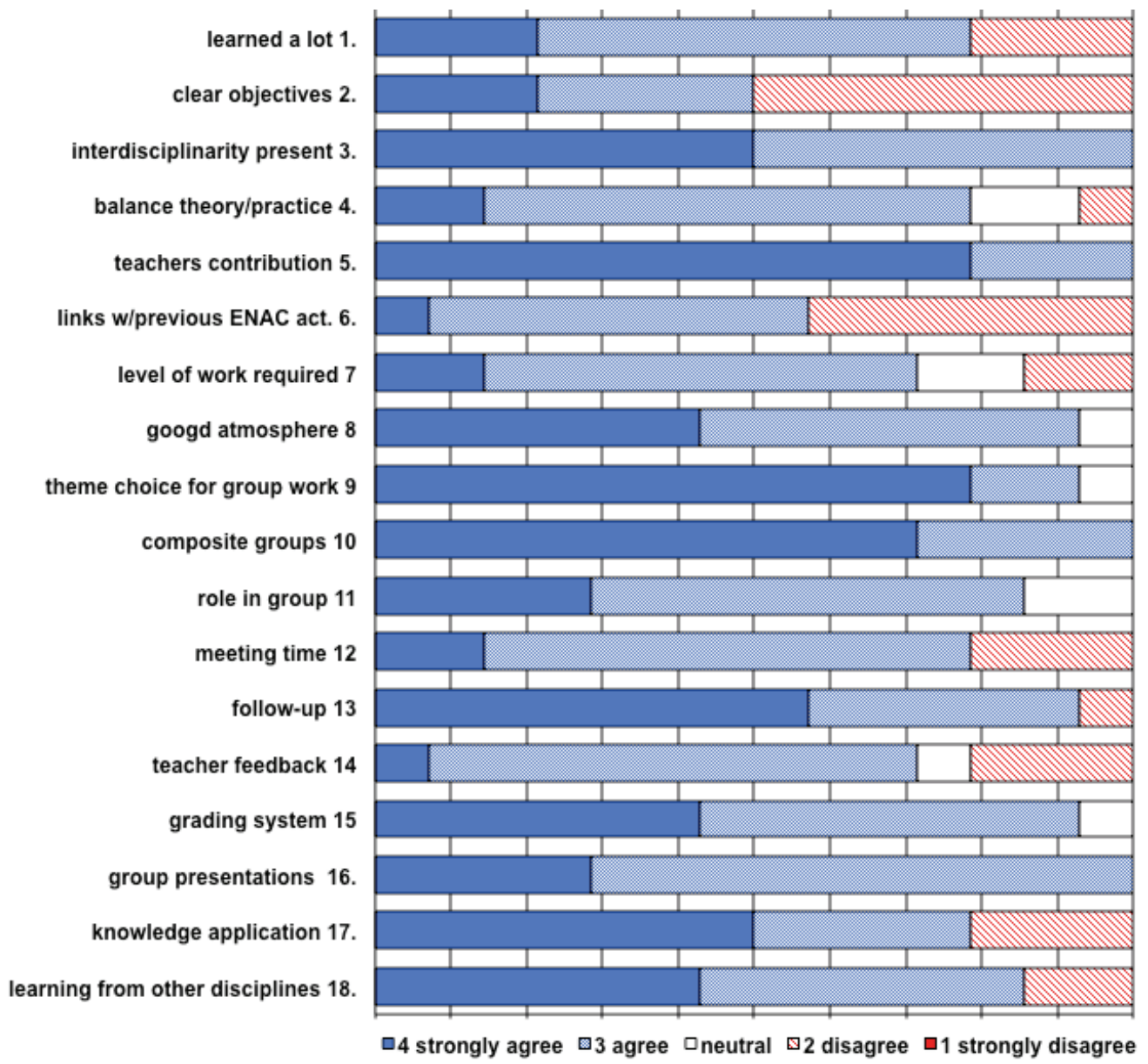

The student evaluation highlighted also some key points necessary to make a success of this kind of courses:

- $\quad$ the objectives must be well presented to students in order for them to be able to understand expected learning and working outcomes. The outcome requirements must be adapted to knowledge acquired by them in prior courses;

- the organisation of the course in two phases is a good didactic approach. During the first third of the semester (phase analysis of context), the students acquire some basic knowledge about the domains treated during the second phase. It helps them also to understand the constraints induced by the extreme context of Mars before starting their own project design;

- even if the course encourages a global approach, it is also important that the students go deeper into some questions. The subjects to study in details must be proposed by the teachers regarding the specificities of the students design proposals;

- weekly follow-up of the projects by the teaching group are crucial in order to organise properly work of each students group and should stimulate and keep them motivated to work outside the classroom for a minimum of $4 \mathrm{~h} /$ week; 
- the iterative process that requires the students to come back on assumptions and on already pre-designed parts is a learning outcome but generally also a new approach for engineer students. It must be one objective to show them engineering reality and to increase their capacity to question assumptions, validity of models, etc.

\section{CONCLUSIONS}

During this course, the students learned to work in an interdisciplinary team and liked the enrichment of composite groups from the three programs. The fact that everyone had a key role, which valorise his, her, specificity is a very nice outcome of the evaluation.

It was the first project where students saw the iterative process of design under multiple constraints. Even if it got the students sometimes frustrated, increasing their capacity to put in question assumptions, validity of models, etc. is a learning result that should be emphasized.

This experience showed the interest of space exploration for its links with Earth challenges regarding how to build better, spare energy, the need to close loops and innovate on Earth in order to achieve sustainability. They were confronted with difficulties such as breeding without earth (organic soil), managing energetic resources/storage and, to their own surprise, that it was impossible to do without a nuclear power source (at least for the early stages of colonization). Finally, they learned the need for closing loops as nothing should be left untreated, left dissipated with the associated health and environmental hazards, even if we currently do it daily on Earth. With this life-cycle thinking, they had the opportunity to integrate some of the many ways to implement upstream ecodesign and downstream waste and co-product valorisation in the project framework of building, exploiting and living in a Mars base.

\section{AKNOWLEDGMENTS}

The authors wish to thank here Pierre Brisson, Dr. Anton Ivanov, Christophe Lasseur and Prof. Claude Nicollier for their availability and kindness in discussing with the students. They wish also to thank the motivated students that took the risk in participating in this new learning unit: F. Ackermann, F. Amblard, G. Briguet, F. Burri, O. Chollet, A. Hansen, G. Jutzeler, G. Kayser, G. Lopez, D. Madöry, M. Menoud, J. Monnet, A. Meyer, C. Pitteloud, C. Rosat, T. Schutter, and J. Senn. Last but not least, to Mme Nadine Stainier (CRAFT) for the pedagogical evaluation.

\section{REFERENCES}

Buckminster Fuller, R. 1969. Operating Manual For Spaceship Earth. Zürich: Lars Müller Publishers, 2008 reprint, ISBN 978-3037781265.

Brisson, P. 2012, Vivre sur Mars, seminar given within ENAC Learning Unit, the Mars society, Switzerland, http://www.planete-mars-suisse.com/ (unpubl).

Erkman, S. 1997. Industrial ecology, an historical view. Journal of Cleaner Production 5(1-2): 87-95.

European space agency - ESA 2006, Melissa research project, Advanced life support, European Space Agency, http://ecls.esa.int/ecls/?p=aboutmelissa.

Godia, F., J. Albiol, et al. (2002). "MELISSA: a loop of interconnected bioreactors to develop life support in Space." Journal of Biotechnology 99(3): 319-330.

Ivanov, A. 2012, La planète Mars, seminar given within ENAC Learning Unit, EPFL, Lausanne, Switzerland (unpubl).

Lasseur, Ch. 2012, MELISSA: recent developments and remaining challenges of ESA's life support system, seminar given within ENAC Learning Unit, ESA, European Space Research and Technology Centre (ESTEC), The Netherlands, http://www.esa.int/esaCP/ (unpubl).

Nicollier, C. 2012, Personal experience on living in space, seminar given within ENAC Learning Unit, EPFL, Lausanne, Switzerland (unpubl).

Poughon, L., B. Farges, et al. 2009. Simulation of the MELiSSA closed loop system as a tool to define its integration strategy. Advances in Space Research 44(12): 1392-1403. 